\title{
Impact analysis of climate change for an Alpine catchment using high resolution dynamic downscaling of ECHAM4 time slices
}

\author{
Harald Kunstmann, Katrin Schneider, Renate Forkel and Richard Knoche \\ Institute for Meteorology and Climate Research (IMK-IFU), Forschungszentrum Karlsruhe, Kreuzeckbahnstrasse 19, 82467 Garmisch-Partenkirchen, Germany
}

Email for corresponding author: harald.kunstmann@imk.fzk.de

\begin{abstract}
Global climate change affects spatial and temporal patterns of precipitation and so has a major impact on surface and subsurface water balances. While global climate models are designed to describe climate change on global or continental scales, their resolution is too coarse for them to be suitable for describing regional climate change. Therefore, regional climate models are applied to downscale the coarse meteorological fields to a much higher spatial resolution to take account of regional climate phenomena. The changes of atmospheric state due to regional climate change must be translated into surface and sub-surface water fluxes so that the impact on water balances in specific catchments can be investigated. This can be achieved by the coupled regional climatic/hydrological simulations presented here. The non-hydrostatic regional climate model $M C C M$ was used for dynamic downscaling for two time slices of a global climate model simulation with the GCM ECHAM4 (IPCC scenario IS92a, 'business as usual') from $2.8^{\circ} \times 2.8^{\circ}$ to $4 \times 4 \mathrm{~km}^{2}$ resolution for the years 1991-1999 and 2031-2039. This allowed derivation of detailed maps showing changes in precipitation and temperature in a region of southern Germany and the central Alps. The performance of the downscaled ECHAM4 to reproduce the seasonality of precipitation in central Europe for the recent climate was investigated by comparison with dynamically downscaled ECMWF reanalyses in $20 \times 20 \mathrm{~km}^{2}$ resolution. The downscaled ECHAM4 fields underestimate precipitation significantly in summer. The ratio of mean monthly downscaled ECHAM4 and ECMWF precipitation showed little variation, so it was used to adjust the course of precipitation for the ECHAM4/MCCM fields before it was applied in the hydrological model. The high resolution meteorological fields were aggregated to 8-hour time steps and applied to the distributed hydrological model WaSiM to simulate the water balance of the alpine catchment of the river Ammer $\left(c .700 \mathrm{~km}^{2}\right)$ at $100 \times 100 \mathrm{~m}^{2}$ resolution. To check the reliability of the coupled regional climatic/hydrological simulation results for the recent climate, they were compared with those of a stationbased hydrological simulation for the period 1991-1999. This study shows the changes in the temperature and precipitation distributions in the catchment from the recent climate to the future climate scenario and how these will affect the frequency distribution of runoff.
\end{abstract}

Keywords: coupled climate-hydrology simulations, dynamic downscaling, distributed hydrological modelling, ECHAM4 climate scenario, alpine hydrology

\section{Introduction}

Climate change can have severe ecological and economical impacts. Water managers, in particular, are interested in whether flood risk and water availability in specific catchments will change. Global climate models with resolutions ranging from about $310 \times 200 \mathrm{~km}^{2}$ (resolution T42 in central Europe) to $125 \times 80 \mathrm{~km}^{2}$ (resolution T106) are unsuitable for describing regional climate.so that regional climate models have to be applied. This is especially true for alpine catchments, where grid resolutions of the order of several kilometres are required to account for terrain-driven phenomena such as orographically-induced precipitation (Lee-Luv effects).
In this study, the non-hydrostatic regional climate model MCCM (Grell et al., 2000a, b) was used, dynamically, to downscale to catchment scale the results of the ECHAM4 global climate model (Roeckner et al., 1996). The scenario IS92a ('business as usual' emission assumptions) was chosen; this assumes an increase in atmospheric $\mathrm{CO}_{2}$ concentrations of $28 \%$ (from $350 \mathrm{ppm}$ to $450 \mathrm{ppm}$ ) between 1990 and 2030. The $\mathrm{CO}_{2}$ projections of IS92a lie between the two popular IPCC SRES (Special Report on Emission Scenarios) scenarios A2 and B2.

The regional climate model $M C C M$ was applied using three successive nests down to $4 \times 4 \mathrm{~km}^{2}$. The resulting meteorological fields were passed in turn to a distributed 
hydrological model which calculated the surface and subsurface water balance of the catchment at a horizontal resolution of $100 \times 100 \mathrm{~m}^{2}$.

Three different uncertainties in the coupled regional climatic/hydrological simulations can be distinguished:

(A) The uncertainty of the regional climate model in simulating observed spatial and temporal precipitation climatology;

(B) The uncertainty arising from the interpolation of regional climate model outputs to the grid points of the hydrological model;

(C) The uncertainty of the hydrological model in reproducing observed discharges when run with interpolated meteorological station data for specific episodes.

To address the different uncertainties, the frequency analysis of the following runoff characteristics was compared:

(1) runoff simulated using dynamically downscaled ECHAM4 meteorological fields for 1991-99;

(2) runoff simulated using interpolated meteorological station data for 1990-99;

(3) runoff observations for 1990-99.

To observe the impact of climate change on the runoff frequency distribution in the catchment,

(4) runoff simulated using dynamically downscaled ECHAM4 meteorological fields for 2031-39

was calculated.

Comparison between (1) and (2) allowed a joint uncertainty estimation of issues $\mathrm{A}$ and $\mathrm{B}$. Comparison between (2) and (3) allowed isolated uncertainty estimation of issue C. Comparison between (1) and (3) allowed estimation of the total uncertainty of the coupled regional climatic/hydrological simulation.

\section{Literature review}

In general, three types of downscaling methods can be distinguished: explicit dynamic downscaling, statistical downscaling and combinations (statistical-dynamic downscaling). While explicit dynamic downscaling methods generally use 3-dimensional regional fine-mesh atmospheric models nested into the domain of a GCM, statistical downscaling methods use regional and global observations to derive statistical relations between regional scale anomalies and corresponding anomalies on a scale large enough to be resolved by a GCM. Combined statistical- dynamic downscaling methods link global and regional model simulations through statistics derived for large scale weather types (Fuentes and Heimann, 2000). An overview on downscaling global climate models for hydrological analysis is given in Prudhomme et al. (2002).

Bardossy et al. (2002) downscaled precipitation and temperature statistically, using a fuzzy rule-based method of circulation pattern classification. Stehlik and Bardossy (2002) extended the approach to account for spatial correlations. Burlando and Rosso (2002a, 2000b) described the stochastic modelling of temporal rainfall from GCM precipitation fields for the Arno river in central Italy. Statistical downscaling methods were also applied in the EU funded project CC-HYDRO (1999) that investigated the impact of climate change on river basins under different climatic conditions for catchments in Austria, Germany, Greece and Italy. Menzel et al. (2002) show how changes in temperature and rainfall regimes can lead to significant changes in flood risk for three meso-scale catchments in Germany.

Coupled meteorological-hydrological simulations by explicit dynamic downscaling of global reanalyses have been presented by Westrick et al. (2002) who describe the performance of a hydro-meteorological forecast system for mountainous catchments and the coupling between MM5 and the distributed hydrological model DHVSM (Wigmosta et al., 1994). Also, to predict peak flows, Jasper et al. (2002) compared the performance of five different high-resolution numerical weather prediction models (with resolutions between $2 \times 2$ and $14 \times 14 \mathrm{~km}^{2}$ ). Yu et al., (1999) ran a hydrological model with results from MM5 for a basin of $14700 \mathrm{~km}^{2}$. Kunstmann and Stadler (2003) presented results for high resolution coupled meteorological-hydrological simulations for the alpine catchment of the river Mangfall. Kunstmann and Stadler (2003), using an extremely high resolution $\left(2 \times 2 \mathrm{~km}^{2}\right)$ of the meteorological model, found very good agreement between observed and simulated discharges at 18 gauges for the year 1997. Kleinn (2002) used a surrogate climate scenario and downscaled meteorological fields dynamically to investigate the impact of climate change on runoff of the Rhine. Arnell (1998) applied climate change scenarios for the year 2050 from different GCM simulations to a $0.5 \times 0.5^{\circ}$ hydrological model with daily time steps.

The present study uses the dynamic approach and the final high resolution of $4 \times 4 \mathrm{~km}^{2}$ that is able to account for the complex orography of alpine catchments. Because of the extremely CPU-demanding simulations, the time slice was restricted to nine years of both recent and future climates.

Alpine catchments present unique challenges. Steep gradients can cause the response times of runoff peaks after 
precipitation events to be extremely short. The decrease in temperature with altitude can result in catchments only a short distance apart appearing in different climatic zones. Snow dynamics influence runoff behaviour significantly. All too often, very little information on groundwater and hydrogeology is available. All these constraints hold true for the Ammer catchment.

\section{The Alpine catchment of the River Ammer}

The Ammer catchment extends to $710 \mathrm{~km}^{2}$ in southern Bavaria (Fig. 1) and drains into Lake Ammersee, located $50 \mathrm{~km}$ south-west of Munich in Germany. The landscape of the alpine and prealpine drainage basin is characterised by high spatial geological and pedological differentiation, a complex orography and corresponding specific climatological conditions. The highest elevation in the catchment is $2185 \mathrm{~m}$ (Kreuzspitze) and the outflow into the Lake Ammersee is $533 \mathrm{~m}$ a.s.l. (Fig. 2).

The catchment can be divided into two landscape units: the prealpine hill country and moorland and the SwabianUpper Bavarian foothills of the Alps. The main geological units are the lime-alpine zone in the southern part, the flysch zone bordering in the north, the folded molasses and the unfolded molasses in the northern part of the catchment.

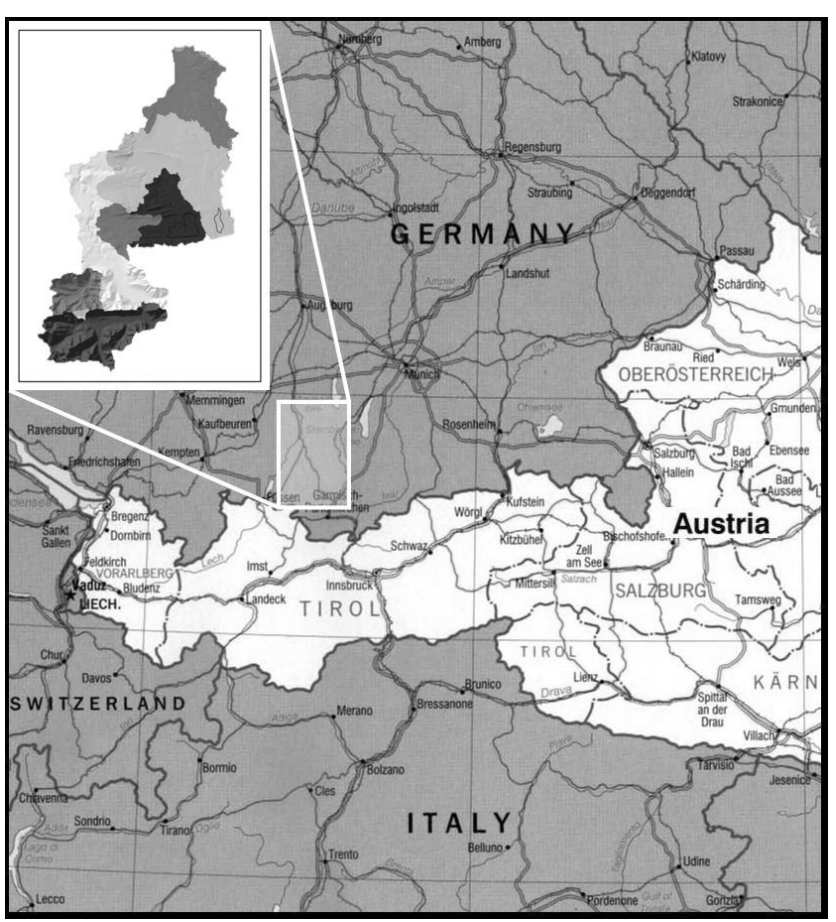

Fig. 1. Location of the Ammer catchment in southern Germany and its sub-catchments.
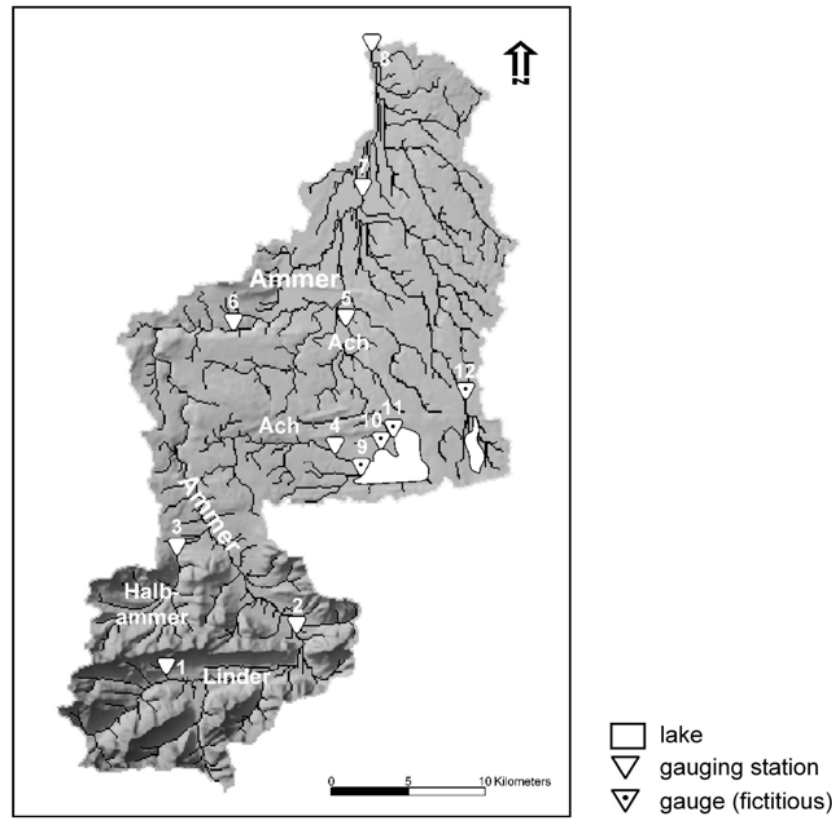

Fig. 3. Relief Map of the Ammer River catchment including the location of 8 gauges.

Digital elevation, soil and vegetation data were derived in the RAPHAEL-project (Raphael, 2000) in which the catchment of the Ammer River (among other European alpine catchments) was investigated.

Climate in the catchment can be characterised as cooltemperate and sempiternal humid. Due to the relief, all climate variables have latitude- and height-dependent gradients. Long-term mean temperature is $7-8^{\circ} \mathrm{C}$. In the southern mountainous regions, mean temperature reduces to $4.5^{\circ} \mathrm{C}$. Temperature lapse rate is around $0.6^{\circ} \mathrm{C} / 100 \mathrm{~m}$ in summer and $0.45^{\circ} \mathrm{C} / 100 \mathrm{~m}$ in winter. Maximum precipitation is in June in the prealpine region and in July in the alpine region. In the catchment, snow $>10 \mathrm{~cm}$ deep lies for around 130 days year-1 (Ludwig, 2000). The River Ammer flows into Lake Ammersee, which in turn drains (via the river Amper) to the Danube. Altogether, eight gauges are sited in the Ammer catchment.

\section{Methods}

THE DISTRIBUTED HYDROLOGICAL MODEL WASIM

The distributed hydrological model WaSiM (Schulla and Jasper, 2000) was used in hydrological simulation of the Ammer catchment. WaSiM uses physically based algorithms for the majority of process descriptions, such as an infiltration approach after Green and Ampt (1911), 
estimation of saturation time after Peschke (1987), and solving the Richards equation (Richards, 1931; Phillip, 1969 ) for the soil water fluxes in the unsaturated zone (Jasper et al., 2002). The dependence on soil moisture content of the soil suction head and the hydraulic conductivity is parameterised according to van Genuchten (1976). Interflow is calculated in defined soil layers, depending on suction, drainable water content $(d)$, hydraulic conductivity $(k)$ and gradient. Surface runoff is routed to the sub-basin outlet by subdividing the basin into flow time zones. Retention is approached by applying a single linear storage to the surface runoff in the last flow time zone (with recession constant $\left.k_{d}\right)$. Translation and retention of interflow is treated similarly (recession constant $k_{i}$ ). Potential and real evapotranspiration, soil- and vegetation-specific, is calculated according to Penman-Monteith (Monteith, 1975; Brutsaert, 1982). Interception is accounted for by a bucket approach. Snow accumulation and snow melt are addressed according to Anderson (1973) and Braun (1985). Surface runoff is created for each grid cell as the sum of infiltration excess and snow melt along the topographic gradient towards the river. It is assumed that saturated hydraulic conductivity decreases (dependent on soil texture) with depth according to a recession constant $k_{\text {rec }}$. Discharge is routed by a kinematic wave approach using different flow velocities for different water levels in the channel. After the translation of the wave, a single linear storage is applied to the routed discharge to account for diffusion and retention (Schulla and Jasper, 2000). WaSiM was applied with an integrated 2D groundwater flow model, coupled dynamically to the unsaturated zone. The uppermost (and, in this study, single) aquifer is assumed to be unconfined. Infiltration from rivers into groundwater and exfiltration (which is the base flow) from groundwater into rivers is calculated using the hydraulic gradient and the colmation (in- and exfiltration resistance) at the river bed. WaSiM does not solve the heat flux balance in the soil/subsurface; therefore, it cannot account for frozen soil effects.

WaSiM was applied at a spatial resolution of $100 \times 100 \mathrm{~m}^{2}$ and a temporal resolution of eight hours. It was calibrated intensively for the hydrological year 1997 by coupling WaSiM to the parameter estimation tool PEST which fits modelled to observed discharges based on the MarquardtLevenberg algorithm (Kunstmann and Krause, 2004). Data from 15 meteorological stations in the surroundings of the Ammer catchment are used in the 'station-interpolated' simulations. However, none of the stations lies inside the catchment; only one is at the edge and this limits, significantly, the quality of values of interpolated precipitation. Horizontal interpolation was performed by inverse distance weighting; in the case of temperature interpolation, an altitude-dependent regression was applied. Unlike temperature, wind, humidity, radiation and precipitation are not dependent primarily on elevation, so no altitude-dependent regression for these variables was determined. However, in complex terrain, a purely geometric interpolation of precipitation across narrow valleys and ridges can lead to significant errors in the precipitation input for the model, particularly when few stations are available.

\section{THE REGIONAL CLIMATE MODEL MCCM}

The coupled simulations were performed using the nonhydrostatic regional climate model MCCM (Grell et al., 2000a, b), based on the mesoscale meteorological model Modell MM5 (Dudhia, 1993; Grell et al., 1994). MCCM calculates the meteorological fields required to drive WaSiM. Time slices of a global climate simulation with ECHAM4 (Roeckner et al., 1996) in T42 resolution $\left(\right.$ c. $\left.2.8^{\circ} \times 2.8^{\circ}\right)$ were used to provide driving boundary fields for $M C C M$. ECHAM4 fields were downscaled dynamically using three nests with resolutions of $60 \times 60 \mathrm{~km}^{2}, 20 \times 20 \mathrm{~km}^{2}$ and $4 \times 4 \mathrm{~km}^{2}$ to southern Germany and, in particular, to the Ammer catchment (Fig. 3). The model top was at 100 mbar. Terrain following coordinates and 25 vertical layers were used. Convective, subgrid-scale precipitation was parameterised according to Grell et al. (1994). Microphysics was calculated according to Reisner et al. (1998); this distinguishes water vapour, cloud water, cloud ice, rain and snow. The turbulent fluxes in the planetary boundary layer

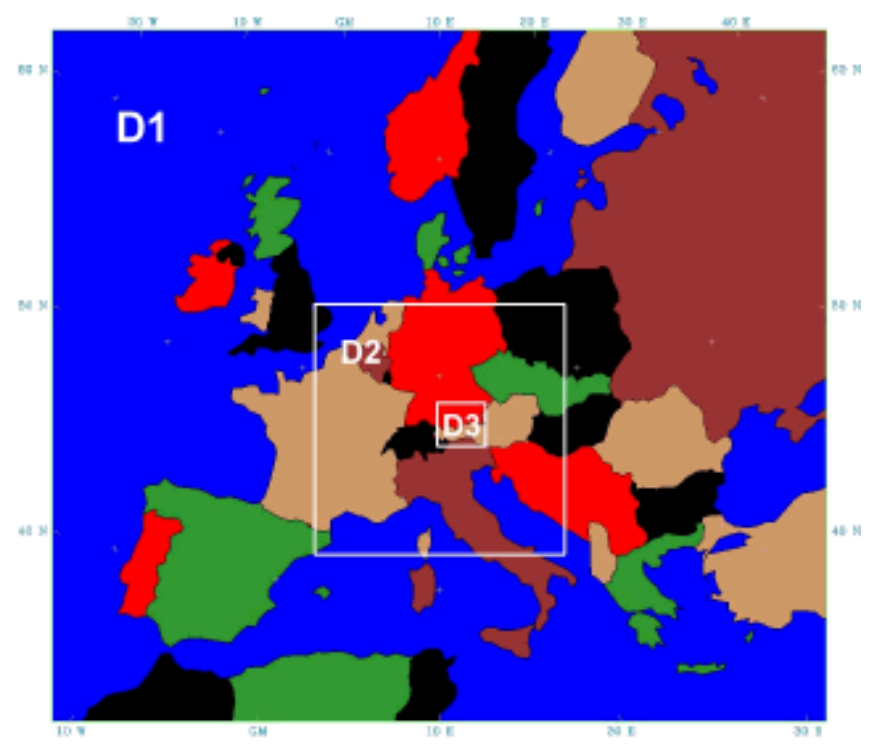

Fig. 3. The regional climate model MCCM was applied in 3 nests dynamically downscaling the ECHAM4 scenario IS-92 a from T42 resolution $\left(2.5 \times 2.5^{\circ}\right)$ to $4 \times 4 \mathrm{~km}^{2}$. 
were parameterised according to Burk-Thompson, (1989). Feedback between soil moisture, temperature, vegetation and atmosphere was accommodated by a fully two-way coupled Land Surface Model (LSM) (Smirnova et al., 1997). The LSM uses six layers down to $3 \mathrm{~m}$ depth to describe energy and water fluxes at the land surface-atmosphere interface. Snow accumulation and snow melt processes are included. However, compared to WaSiM, the LSM of MCCM cannot rout infiltration excess to the basin outlet and is restricted to a coarse horizontal resolution of the atmospheric part of the model. Domain 3 was simulated with a horizontal resolution of $4 \times 4 \mathrm{~km}^{2}$ which is an extremely high resolution mode for regional climate mode modelling. The high spatial resolution is required to resolve the small scale atmospheric dynamics. Since the hydrostatic assumption fails for scales smaller than $10 \times 10 \mathrm{~km}^{2}$, these high resolutions can be achieved only by non-hydrostatic atmospheric models. At this resolution, convective precipitation events are more and more resolved by an explicit microphysics scheme rather than through parameterisation in a sub-grid-scale cumulus scheme. The Grell scheme (Grell et al., 1994) automatically reduces the fraction of sub-grid-scale precipitation to total precipitation as horizontal resolution increases. The resolution chosen required a time step of 12 seconds. The meteorological fields provided by $M C C M$ were averaged over eight hours and passed to the hydrological model, which was given a spin up time of one year (hydrological year 1991, and hydrological year 2031), so that runoff analysis is based on a time series of eight years.

\section{COUPLING STRATEGIES BETWEEN}

HYDROLOGICAL AND METEOROLOGICAL MODEL

The relevant meteorological fields calculated by $M C C M$ are passed directly to WaSiM in a one-way mode via an interface (Fig. 4). Each grid point of the meteorological model is treated as a 'fictitious' meteorological station in the hydrological model. In detail, the meteorological fields are: temperature and relative humidity at $2 \mathrm{~m}$, wind velocity at $10 \mathrm{~m}$, precipitation and incoming radiation. Within the $4 \times 4 \mathrm{~km}^{2}$-resolution of the meteorological model, the meteorological variables are interpolated bilinearily to the $100 \times 100 \mathrm{~m}^{2}$ resolution of the hydrological model. Due to the different grid resolutions, model elevations in the meteorological model differ from model elevations in the hydrological model, so that temperature has been adjusted by an altitude-dependent regression.

\section{Results of regional climate modelling}

Figure 5 shows the mean temperature simulated by the model for 1991-99 for part of domain 2. Comparison of simulated mean annual temperature with interpolated observations presented in BayFORKLIM (1996) shows reasonable agreement, as absolute values differ by less than $1^{\circ} \mathrm{C}$. Specific details, like mean annual temperature, which decrease along the Chech borderline (low mountain range of Bavarian Forest) and in the Bavarian Alps, are also well reproduced. Figure 6 shows the change in evapotranspiration and temperature for domain 3 between 1991-

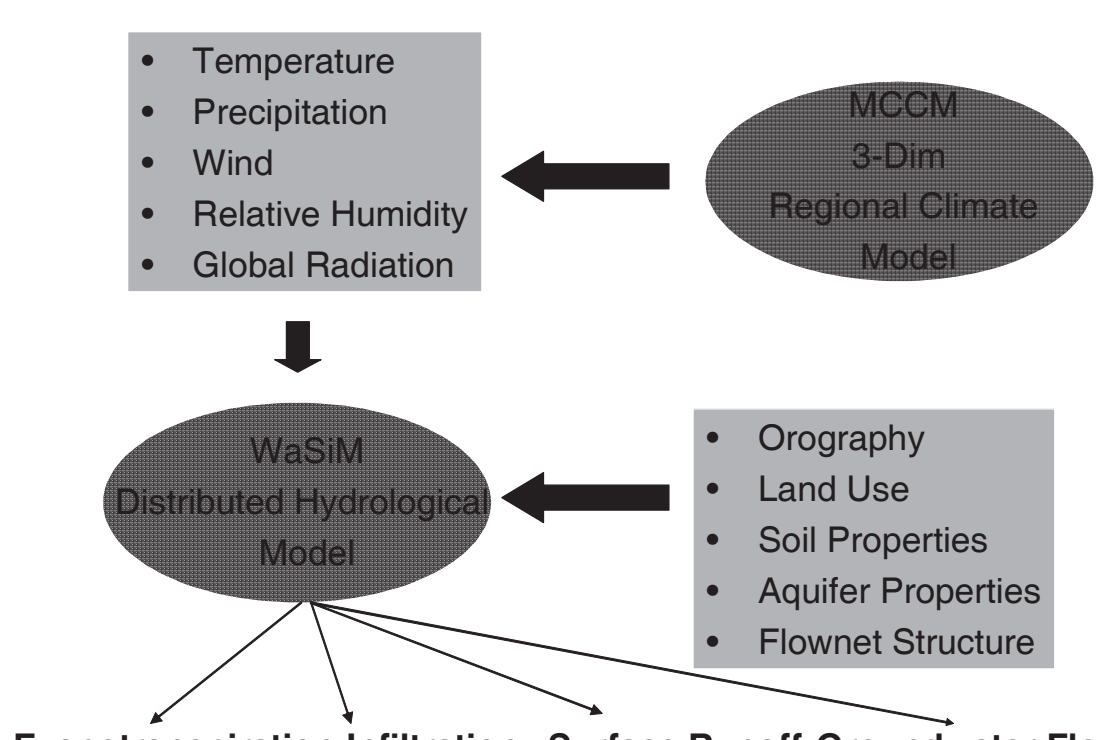

Evapotranspiration Infiltration Surface Runoff Groundwater Flow

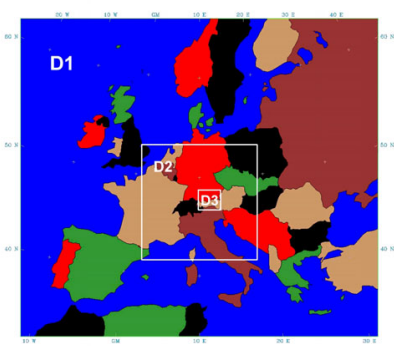

$2.8^{\circ} \times 2.8^{\circ}->4 \times 4 \mathrm{~km}^{2}$ Resolution

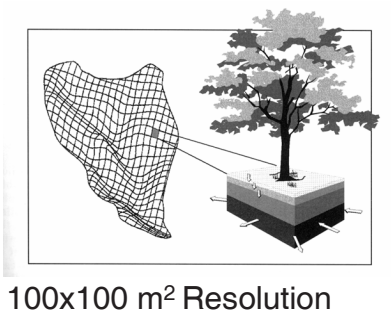

Fig. 4. Coupling scheme between regional climate model MCCM and distributed hydrological model WaSiM 


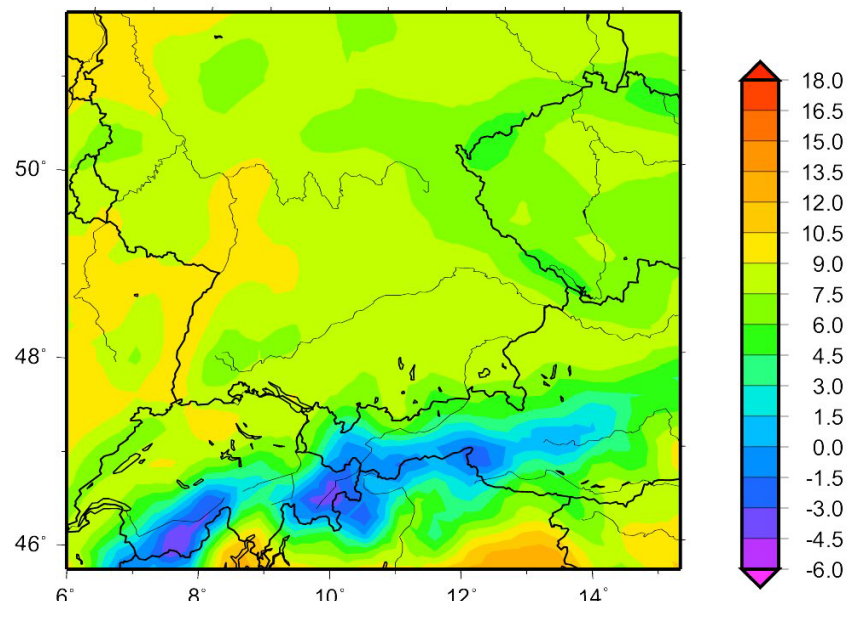

Fig. 5. Mean average temperature $\left[{ }^{\circ} \mathrm{C}\right]$ in domain 2 for 1991-1999.

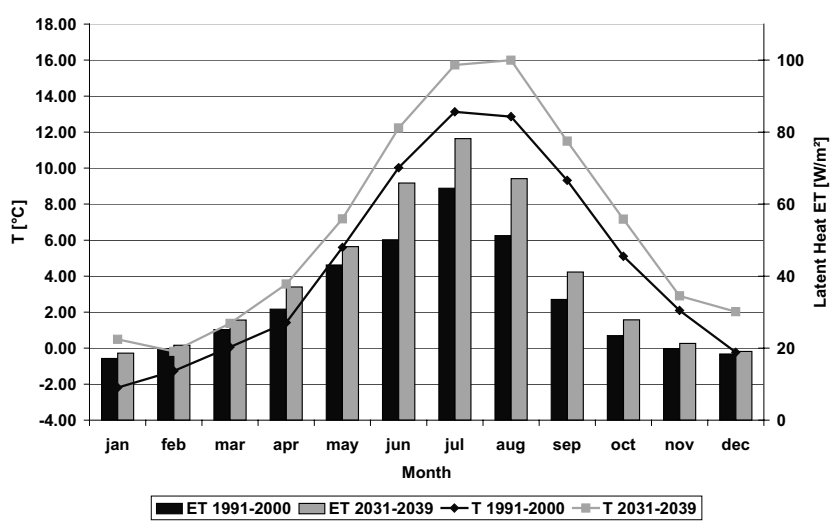

Fig. 6. Change in mean monthly temperature $\left[{ }^{\circ} \mathrm{C}\right]$ and mean monthly latent heat $\left[\mathrm{W} / \mathrm{m}^{2}\right]$ in domain 3 (2031-2039 vs. 1991-1999)

99 and 2031-39. Comparison with BayFORKLIM (2000) shows good agreement with the simulated recent climate annual temperature course. In winter, the increase in temperature is around $2^{\circ} \mathrm{C}$, in spring and autumn $1{ }^{\circ} \mathrm{C}$ and in summer $2.5^{\circ} \mathrm{C}$. Figure 6 also indicates that temperature increases are associated with increases in evapotranspiration (latent heat fluxes). Predicted increases in mean monthly evapotranspiration in summer are $31 \%$ in June and $21 \%$ in July and, in winter, 9\% in January and 5\% in February.

The spatial distribution of temperature change (Fig. 7) shows that temperature change is correlated strongly with elevation and the increase is highest in the Inn valley; it can also vary significantly within short distances, especially in orographically complex terrain. The change in annual precipitation is highest at high elevations.(Figs. 8, 9 and 10). For this scenario, in the northern part of domain 3, precipitation decreased by up to $15 \%$, while in the alpine

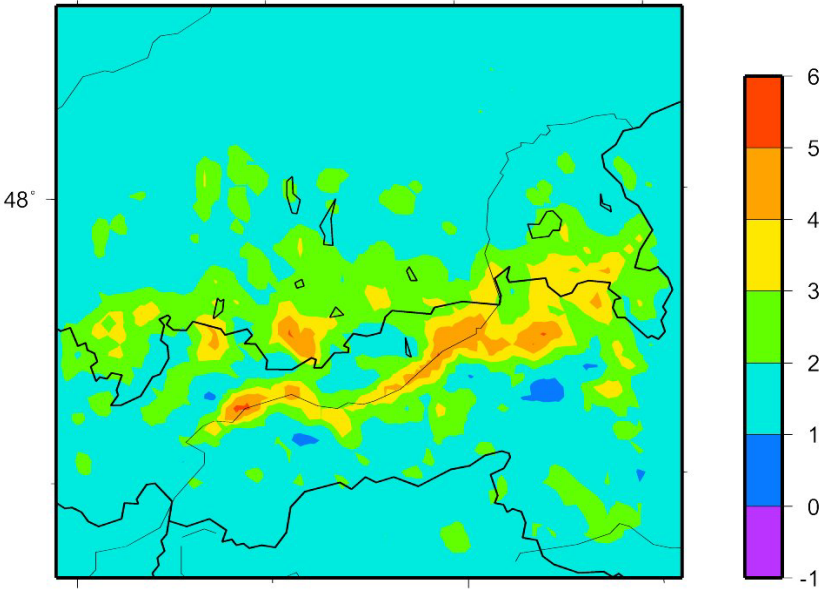

Fig. 7. Change of mean annual temperature $\left[{ }^{\circ} \mathrm{C}\right]$ in domain $3(2031 /$ 2039-1991/1999)

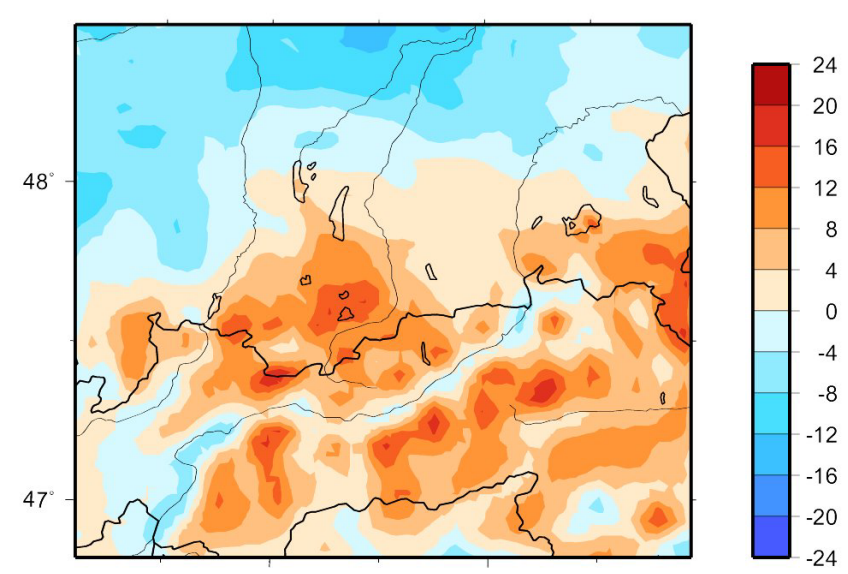

Fig. 8. Change in annual precipitation [\%] (2031/2039-1991/1999)

parts of southern Germany and western Austria, precipitation increased by up to $20 \%$. In winter, most of the alpine parts receive more precipitation (Fig. 9) but, in summer, this is true only for the northern foothills. In the southern regions and, in particular, the Inn valley, precipitation tends to decrease in the summer months of June, July and August (Fig. 10).

However, in summer, both ECHAM4 and the dynamically downscaled meteorological precipitation fields underestimate precipitation significantly. While the maximum precipitation in southern Germany falls in summer (e.g. BayFORKLIM, 1996), ECHAM4-MCCM predicts less precipitation in summer than in winter; the precipitation fields of global ECHAM4 in T42 resolution (Fig. 11) show summers which are too dry. This shortcoming is well known (Liepert and Lohmann, 2001) but the reasons for this are not yet fully understood. Hence, global climate models can 


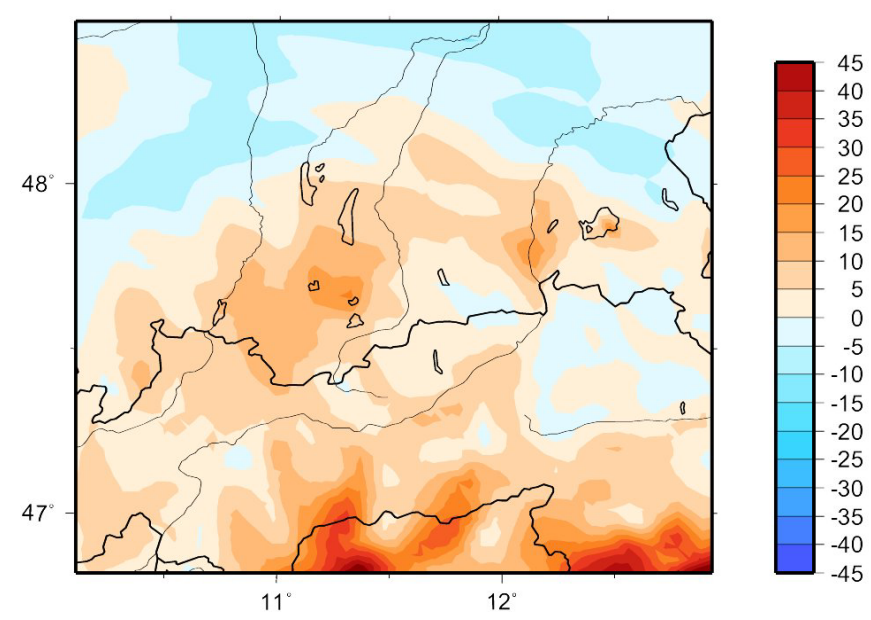

Fig. 9. Change in total winter (DJF) precipitation [\%] (2031/20391991/1999)

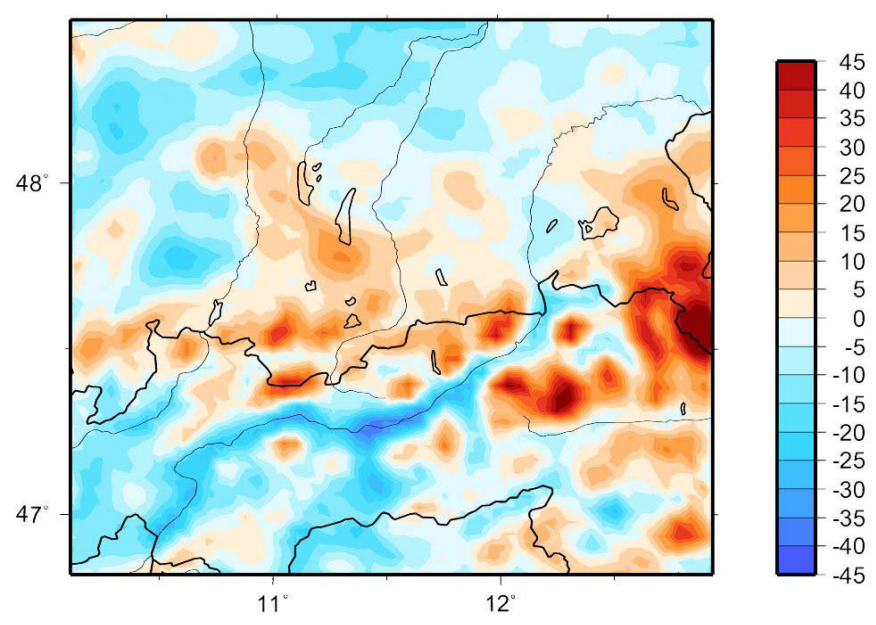

Fig. 10. Change in total summer (JJA) precipitation [\%] (2031/ 2039-1991/1999) be severely limited for specific regions, a shortcoming which cannot be corrected by the downscaling itself, since the air masses entering central Europe are too dry to support even small scale convective precipitation events which could enhance the underestimated summer precipitation.

The quality of the dynamically downscaled ECHAM4MCCM precipitation fields for 1991-99 was investigated by comparing, at a $20 \times 20 \mathrm{~km}^{2}$ resolution, the results for 1979-1993 of dynamically downscaled ECMWF-reanalyses obtained in a similar setup of $M C C M$, but using ECWMF reanalyses as the driving GCM instead of ECHAM4.

The quality of reproduced climatological precipitation at every grid point $(i, j)$ of the $4 \times 4 \mathrm{~km}^{2}$ resolution downscaled ECHAM4 scenario can be described by the ECMWFECHAM4 ratio $k$ (e.g. for January)

$k_{\text {January }}(i, j)=\frac{\frac{1}{15} \sum_{\text {year }=1979}^{1993} \sum_{d a y=1}^{31} E C M W F_{\text {year, January,day }}(i i, j j)}{\frac{1}{9} \sum_{\text {year }=1999}^{1999} \sum_{\text {day }=1}^{30} E C H A M 4_{\text {Recent Climate, year, January, day }}(i, j)}$

(and, correspondingly, for all other months). Here, for every grid point $(i, j)$ of the $4 \times 4 \mathrm{~km}^{2}$-grid, the closest grid point $(i i, j j)$ of the $20 \times 20 \mathrm{~km}^{2} E C M W F-M C C M$ grid is attributed (Fig. 12). If $k$ is close to 1, the ECHAM4-MCCM climatology agrees with the observed $E C M W F-M C C M$ climatology. For $k>1, E C H A M 4-M C C M$ underestimates precipitation, while for $k<1, E C H A M 4-M C C M$ overestimates precipitation for the particular month.

The choice of 15 years for ECMWF reanalyses in the numerator and nine years for ECHAM4 in the denominator

ECHAM4 1991-1999, $2.8^{\circ} \times 2.8^{\circ}$ Resolution, Southern Germany

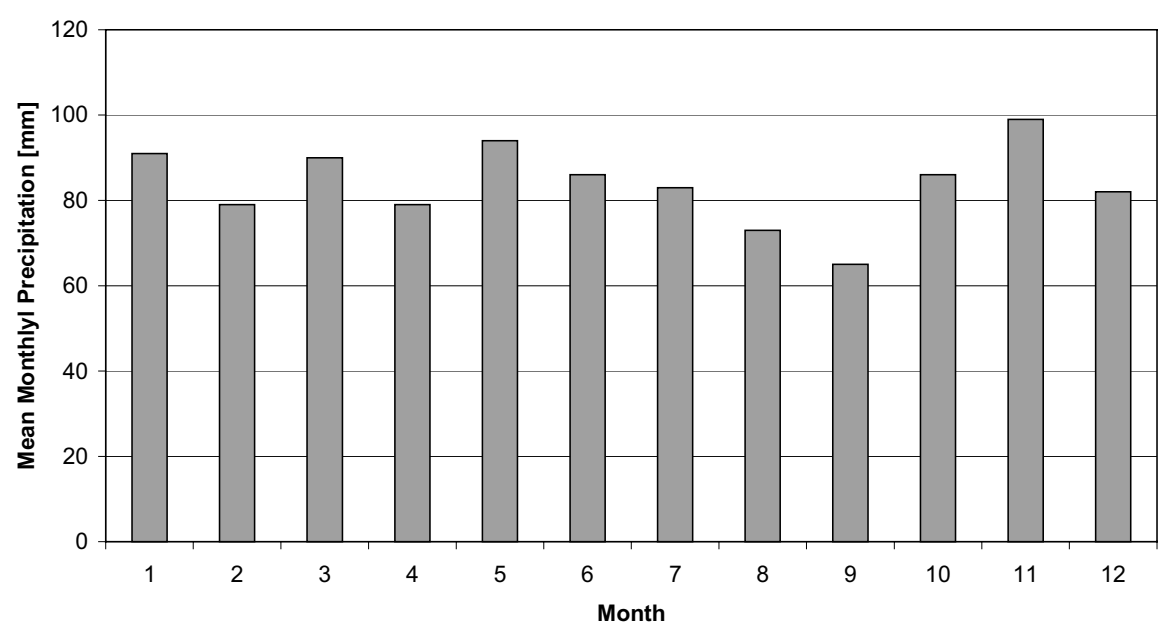

Fig. 11. Mean monthly precipitation in Southern Germany (approximating domain 3) as modelled in the original ECHAM4 in T42 resolution. 
of Eqn. 1 reflects CPU time constraints and data availability. Since the ECHAM4 years 1991-1999 represent fictitious realisations of recent climate, single ECHAM4 years cannot be compared directly with the corresponding real years. Therefore, the sum in the nominator and the denominator of Eqn. (1) do not necessarily have to be calculated over the same period but should both present average recent climate. The total number of years considered for both ECMWF and ECHAM4 simulations is marginal for climatological significance. A limitation of the precipitation correction arises because ECMWF and ECHAM4 have different resolutions. The ECMWF simulations in $20 \times 20 \mathrm{~km}^{2}$ are based on a much coarser and, therefore, smoothed orography compared with the ECHAM4 simulation results.

Figure 13 (a) - (d) exemplifies the ratio $k$ for January, April, July and October. The downscaled climatic scenario is in reasonable agreement with downscaled $E C M W F$-fields for winter, spring and autumn, i.e. the ratio $k$ does not differ significantly from the ideal value of 1 . The spatial distribution of $k$ shows regional differences and patterns: especially in complex terrain (e.g. inner-alpine valleys with steep gradients) where the ratio is higher, whereas $k$ is lower in the foothills and north of the foothills. The highest differences in spatial distribution of $k$ occur in summer, where the alpine parts show higher values than the remaining area. Also, in summer, the downscaled climate scenario underestimates precipitation significantly through most of domain 3. To investigate the spatial and temporal stability of this ratio, its variance is obtained by omitting single years in the sum of the numerator and denominator, thereby

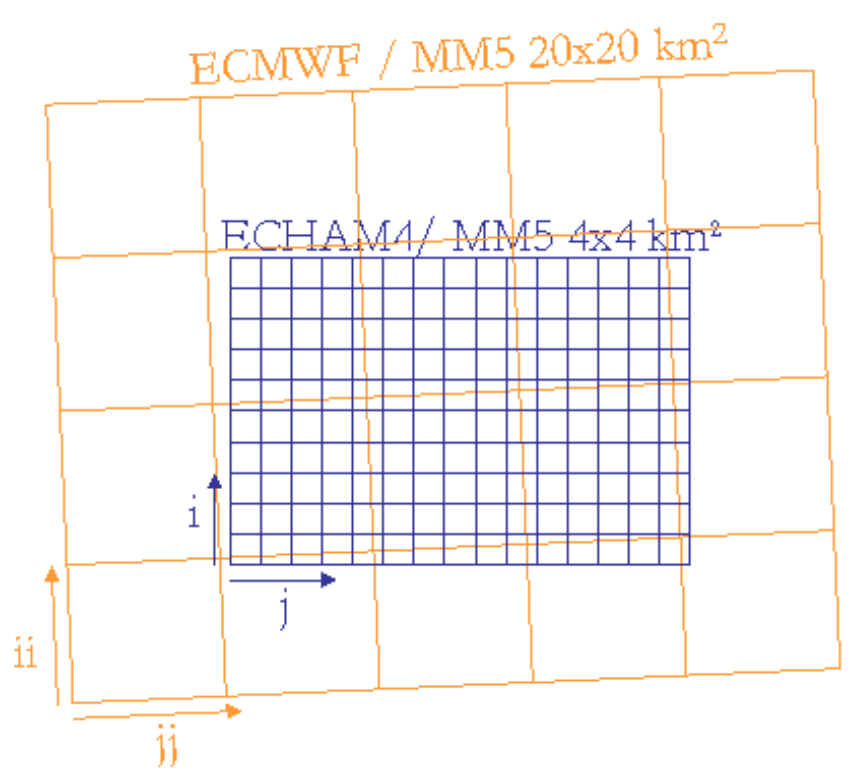

Fig. 12. Attribution of ECMWF grid points to MM5/MCCM grid points obtaining for each month a sample of $15 \times 9=135$ values for $k$, from which the standard deviation $\sigma_{k}$ and the coefficient of variation can be calculated. Figure 14 (a) - (d) shows the coefficient of variation for January, April, July and October; the variation is comparatively small and is generally less than 0.15. Likewise, for the ECMWF-ECHAM4 ratio $k$ itself, regional differences exist. As shown above, the spatial distribution of $k$ tends towards higher values in complex terrain; in the hilly or flat areas values are moderate. The coefficient of variation also shows spatial patterns but these differ from those of the $k$ ratio. Although the coefficient of variation in the inner-alpine valleys have the highest values, these do not extend over the whole alpine orography. This shows that, unlike the ratio $k$, the quality of the coefficient of variation is unaffected by topographic features.

Because reproducibility of temporal and spatial distributions of precipitation is a prerequisite for hydrological modelling, the precipitation fields obtained by the dynamically downscaled ECHAM4 fields are unsuitable; an estimate of precipitation which is shifted in its yearly cycle would inevitably lead to a seasonally shifted simulation of runoff. However, the variability in the fields for the ECMWF-ECHAM4 $k$ ratio is small, so the possibility of using this information to adjust the dynamically downscaled ECHAM4-MCCM precipitation fields was investigated. This was achieved for every gridpoint $(i, j)$ at every time step $t$ by the following transformation (e.g. for January):

$E C H A M 4_{\text {RecentClimate }}(t, i, j)^{\prime}=E C H A M 4_{\text {RecentClimate }}(t, i, j) \times k_{\text {January }}(i, j)$

In the case of the future climate scenario, the following transformation was applied

$E C H A M 4_{\text {FutureClimate }}(t, i, j)^{\prime}=E C H A M 4_{\text {FutureClimate }}(t, i, j) \times k_{\text {January }}(i, j)$

(for the remaining months the transformation was performed accordingly). Figure 15 shows the difference between the original downscaled ECHAM4-MCCM precipitation (in the Ammer catchment) and the precipitation adjusted according to Eqn. 2). Figure 15 (a) shows the recent climate years (1991-99), and Figure 15 (b) the corresponding result for climate simulations for 2031-39, with the seasonality and the overall precipitation amount adjusted.

Applying the corrected ECHAM4-MCMM precipitation fields for hydrological simulations of recent and future climate water balances, the following constraints of the methodology hold:

(1) While the number of ECHAM-MCCM precipitation events remains unchanged, the intensity of each event 
Harald Kunstmann, Katrin Schneider, Renate Forkel and Richard Knoche
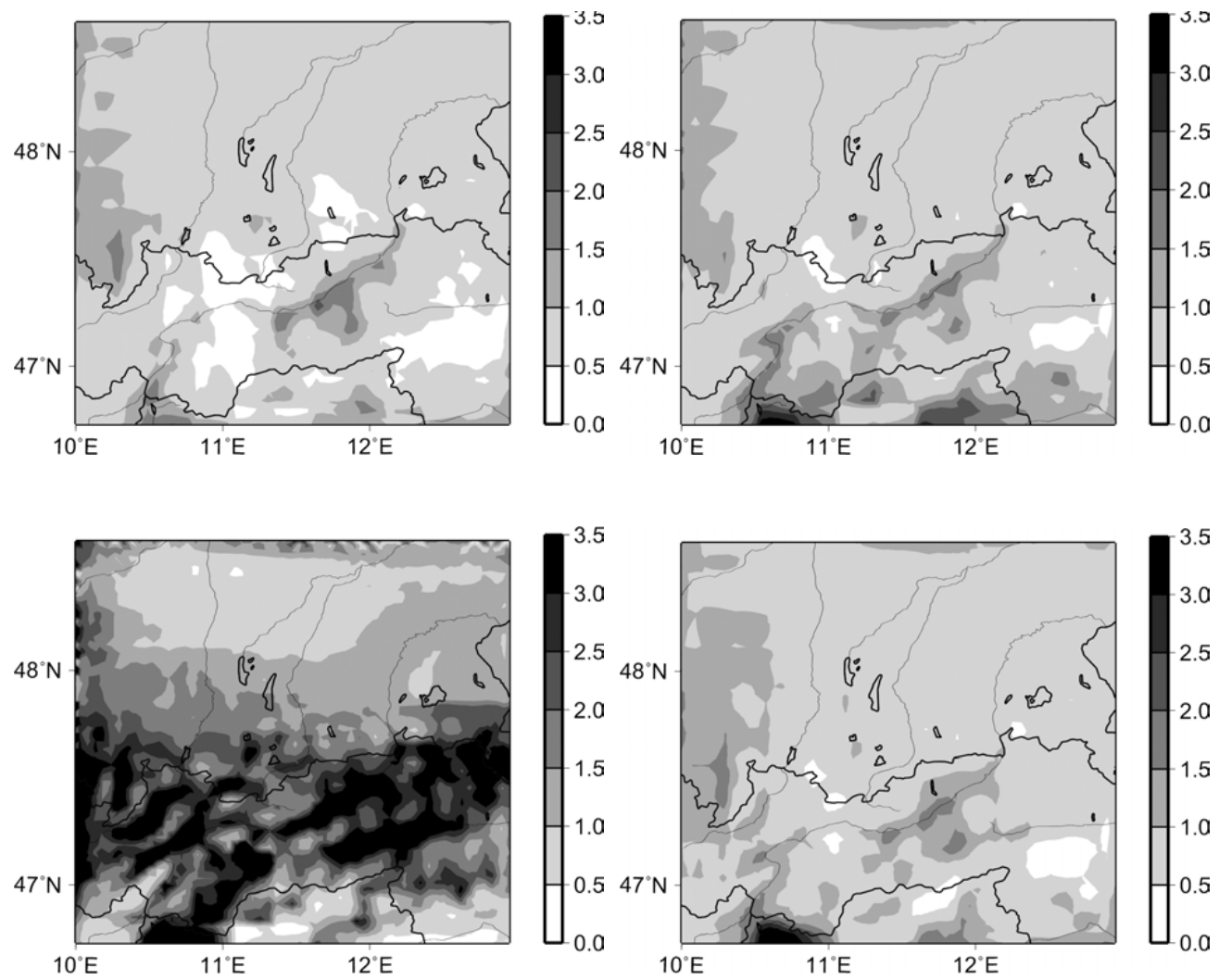

Fig.13. ECMWF-ECHAM4 precipitation ratio k, for January (a; upper left), April (b; upper right), July (c; lower left), October (d; lower right)
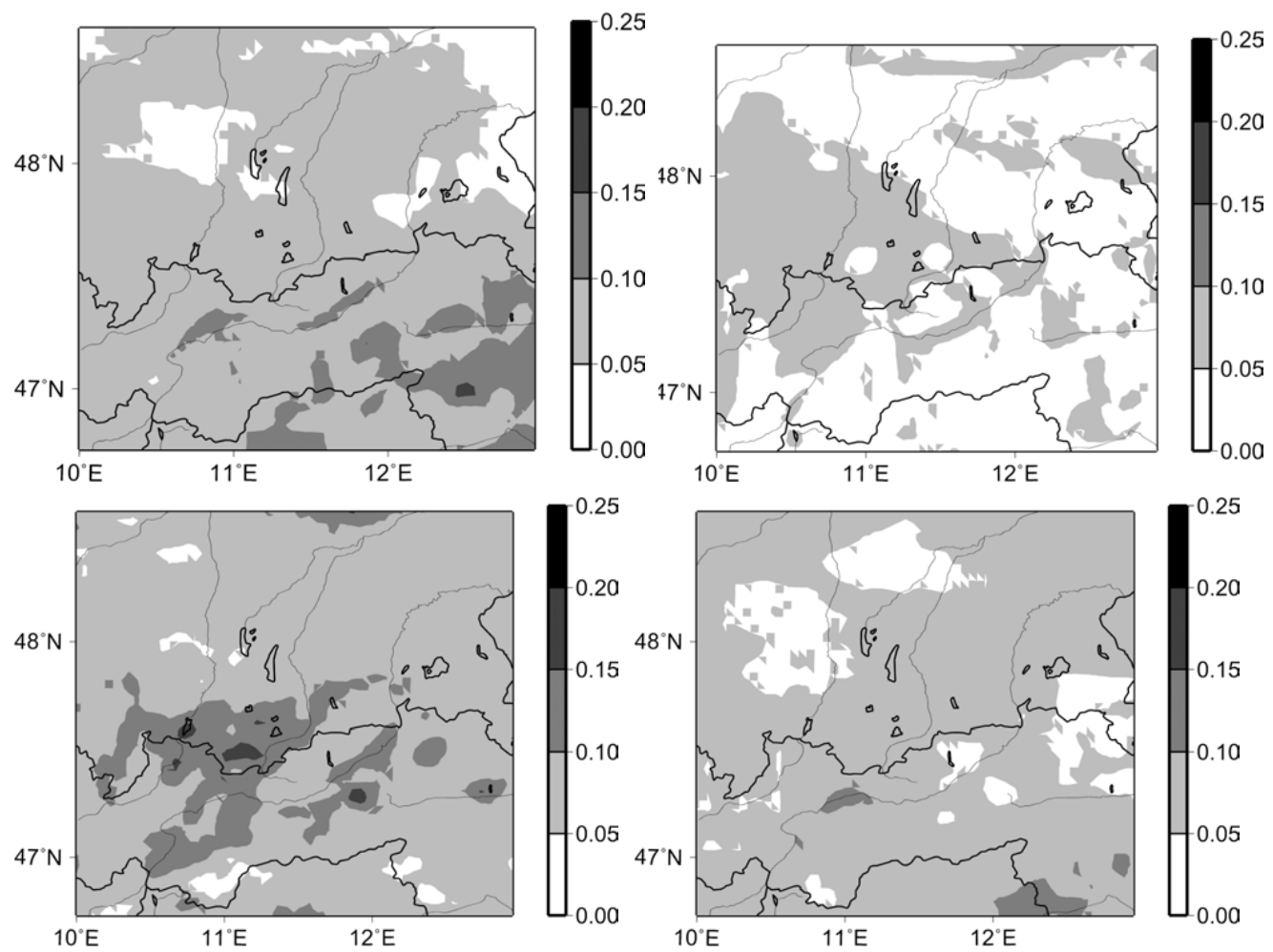

Fig. 14. Coefficient of variation of ECMWF ECHAM4 precipitation ratio $k$, for January (a; upper left), April (b; upper right), July (c; lower left), October (d; lower right) 

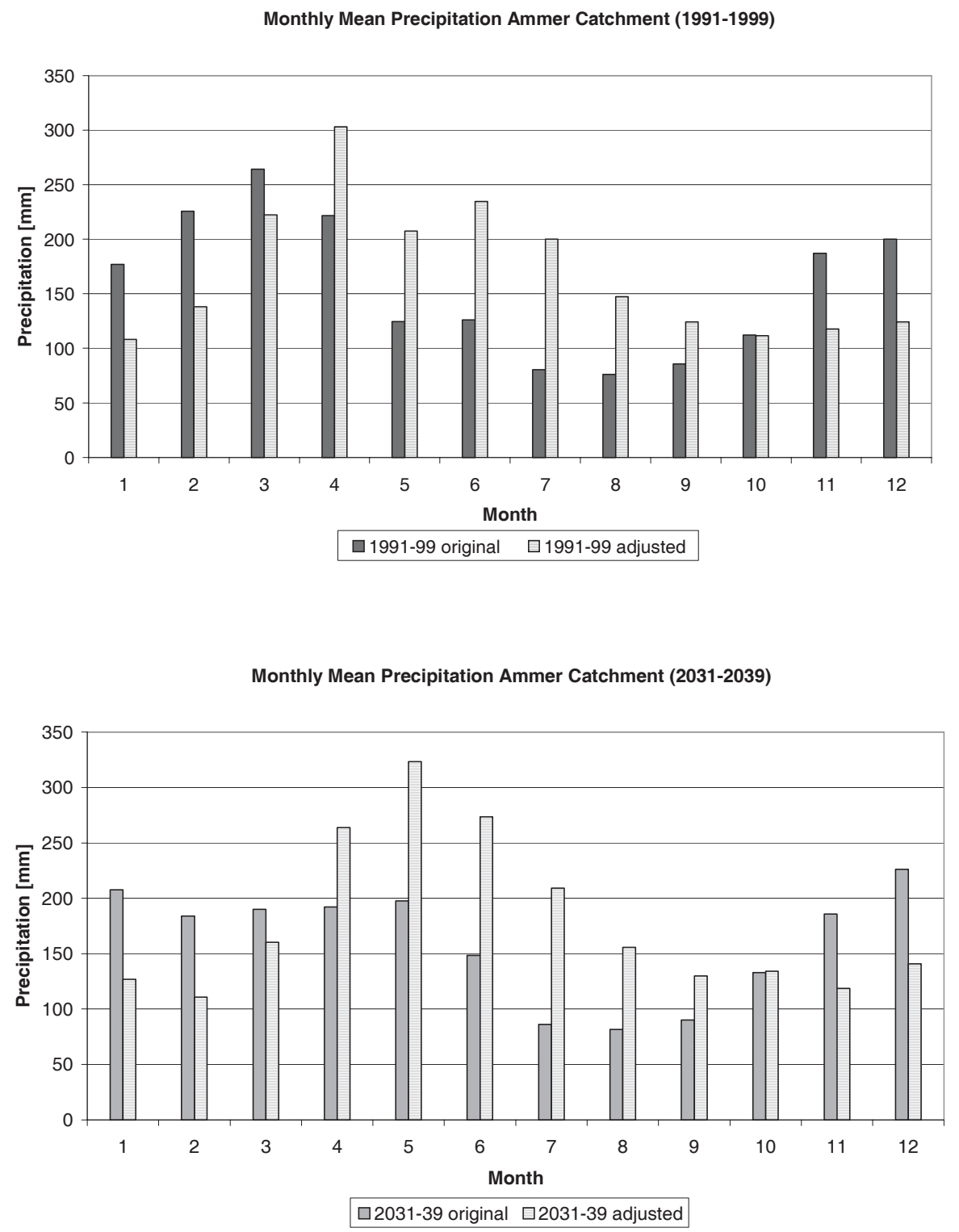

Fig. 15. Monthly mean precipitation in the Ammer catchment; comparison between original and scaled precipitation for recent climate $1991-99$ and future climate 2031-39

is adjusted such that the overall average monthly sum agrees with the ECMWF-derived average monthly values.

(2) Precipitation was adjusted according to a spatially (i.e. at every grid point) different climatological factor averaged over 15 years in the case of $E C M W F$ and over nine years in the case of ECHAM4. Within each month, each precipitation event at a given grid point was adjusted with the same factor $k$.

(3) All the other meteorological fields that are passed from $M C C M$ to WaSiM (wind, temperature, humidity, radiation) remain unchanged. This implies that the precipitation fields are not necessarily consistent with the other meteorological fields.
(4) The ECMWF simulations have a coarser resolution than the ECHAM4-MCCM simulations. This limits the quality of calculations of the factor $k$ because orographic induced precipitation is described with different accuracy in the two simulations.

\section{Results of coupled regional climate/ hydrology simulations}

Four types of hydrological simulations have been performed to investigate the impact of global climate change and the related uncertainties on the water balance in the Ammer 
catchment:

(1) station interpolated hydrological simulation using 15 meteorological stations of the German weather service DWD for the years 1990-1999.

(2) ECHAM4-MCCM driven hydrological simulation for the IS92a scenario years 1991-1999, using corrected precipitation fields.

(3) ECHAM4-MCCM driven hydrological simulation for the IS92a scenario years 2031-2039, using corrected precipitation fields.

(4) ECHAM4-MCCM driven hydrological simulation for the IS92a scenario years 1991-1999; once using the ECMWF-ECHAM4 $k$ ratio plus one standard deviation for precipitation correction, and additionally once using $k$ minus one standard deviation.

The hydrological simulations were analysed for the normalised frequency distribution of discharge at selected gauges. The normalised frequency distribution was calculated according to

$f d\left(q_{i}\right)=\frac{\text { number of } q_{i} \text { within }\left[q_{i}-\frac{\Delta q}{2}<q_{i}<q_{i}+\frac{\Delta q}{2}\right]}{\text { total number of } q_{i}}$

such that

$$
\sum_{q_{i}=0}^{q_{i}=q_{\max }} f d\left(q_{i}\right)=1
$$

holds. $\Delta q=0.5 \mathrm{~m}^{3} \mathrm{~s}^{-1}$ was chosen as class width.

The frequency distribution of case (1) and (2) was compared to the frequency distribution obtained from analysis of observed discharge. Additionally, the frequency distribution of the future climate scenario indicates the expected changes in runoff characteristics. The results for runoff at gauge 3 (Unternogg), a source catchment uninfluenced by constructional changes, are shown in Fig. 16 ; the analysis is restricted to the frequency distribution in the four seasons (DJF, MAM, JJA, SON).

Figure 16 (a) shows the frequency distribution for winter runoff (DJF). The station driven simulation (DWD_Stat) shows a slight bias towards the observed ( $\left.O b s \_g a u g e\right)$ frequency distribution. The ECHAM4-MCCM recent climate frequency distribution (MM5_1992-99), however, is rather close to DWD_Stat, with a slight underestimation of small runoff frequencies and a small overestimation of high runoff frequencies. A clear climate change signal can be seen: MM5_2032-39 shows that the frequency of high runoff values is increased and the number of small runoff values is decreased against MM5_1992-99. Figure 16 b) shows the corresponding analysis for spring time (MAM). Here, DWD_Stat is in good agreement with Obs_gauge. MM5_1992-99 agrees with both DWD_Stat and Obs_gauge but overestimates the frequencies of high runoff values. This shows that MM5_1992-99 does not describe high runoff in spring satisfactorily. Comparison between MM5_1992-99 and MM5_2032-39 shows that total runoff is less in spring in the future climate. A comparison of precipitation between recent and future climates (Fig. 15(a) and (b), adjusted precipitation in each case), indicates a decrease in March and April and a slight increase in May; this explains a decrease in spring runoff. However, the high spatial variability of precipitation change shown in Figs. 8, 9, and 10, particularly at the location of the Ammer catchment, means that runoff from neighbouring sub-catchments can differ because of orographically dependent precipitation changes. Hence, the differences in observed frequencies implies that the uncertainty in the forecast of decreased spring runoff is high. Figure 16(c) presents the frequency analysis for summer months JJA. While the hydrological model is able to describe the runoff (congruency between Obs_gauge and DWD_Stat), the discrepancy between DWD_Stat and MM5_1992-99 shows that the recent climate simulations MM5_1992-99 do not meet observed characteristics and the climate change signal (difference between MM5_1992-99 and MM5_2032-39) carries high uncertainties. If these uncertainties are ignored, total runoff in summer decreases because of increased evapotranspiration rates (Fig. 6). Figure 16(d) describes the frequency distributions for autumn SON.DWD_Stat shows a bias against $\mathrm{Obs \_ gauge} \mathrm{(shift} \mathrm{towards} \mathrm{higher} \mathrm{frequencies)}$ but a surprisingly good agreement with MM5_1992-99. Analysis of MM5_2032-39 reveals that, in autumn, an increase in mean as well as high runoff values can be expected. Detailed analysis of regional climate simulations showed that, in the area of the Ammer catchment, the number of days with precipitation higher than $10 \mathrm{~mm}$ increases by around 3-4 days (i.e. 30\%) in autumn which explains the increase of high runoff values under future climatic conditions.

In the pre-alpine area, such as sub-catchment 4 (Obernach), the agreement between Obs_gauge, DWD_Stat, and MM5_1992-99 is generally better than in the alpine area. This is shown in Fig. 17 (a) winter, (b) spring, (c) summer and (d) autumn. The good agreement in the summer months (JJA) between DWD_Stat and MM5_1992-1999 is also shown for sub-catchments 6 (Peissenberg) and 7 (Weilheim) in Fig. 18 a) and b) However, the differences between MM5_1992-99 and MM5_2032-39 in subcatchment 4 are small, i.e. no major impact of climate change on runoff characteristics according to the IS92a scenario 

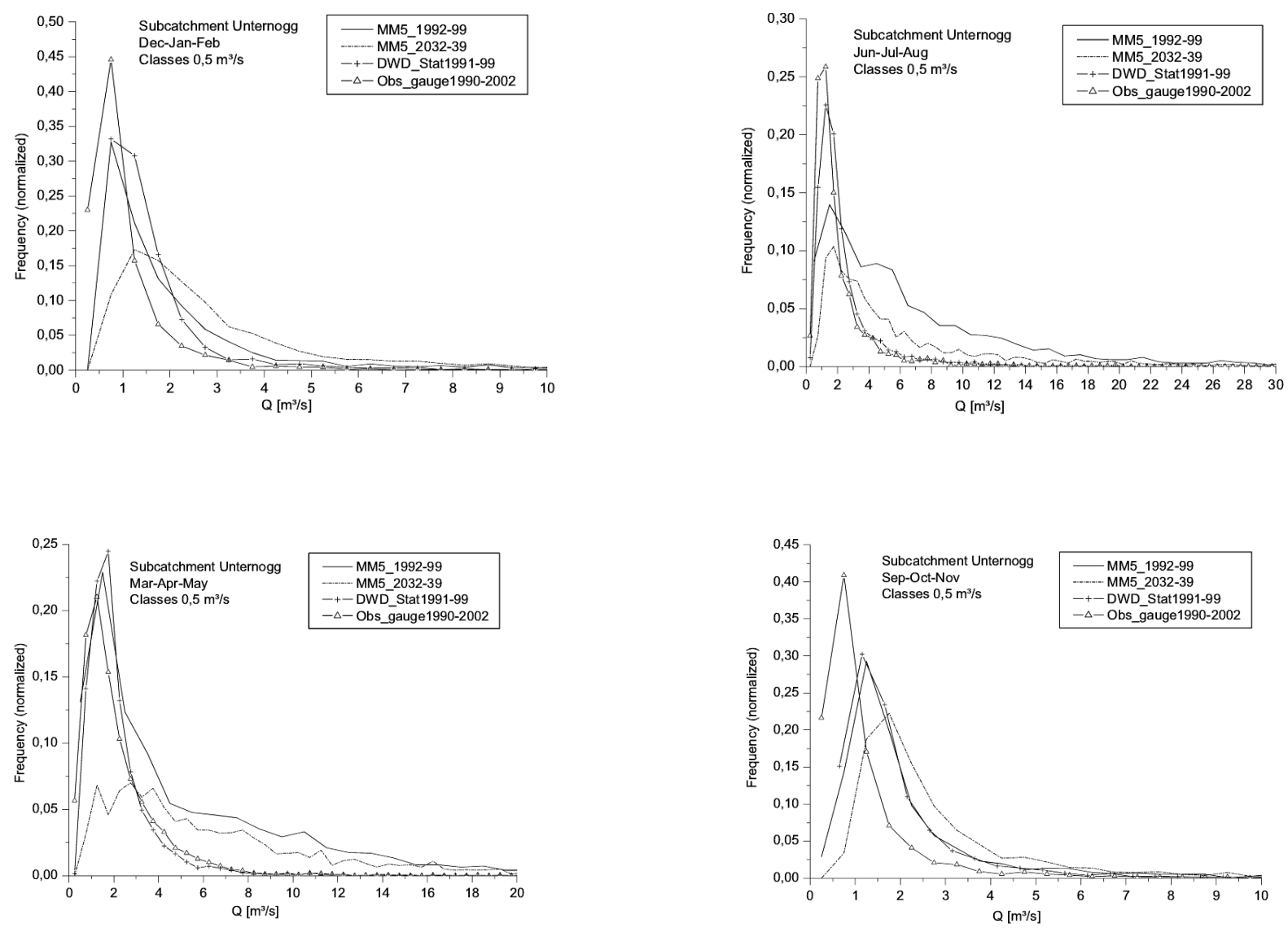

Fig. 16. Comparison between observed FD, station driven modelled FD, and ECHAM4-MCCM driven FDs for 1992-1999 and $2032-2039$ at gauge Unternogg (sub-catchment 3). (a) winter, (b) spring, (c) summer, (d) autumn

can be predicted.

In conclusion, the quality of coupled regional climate/ hydrology simulations is reasonable in the pre-alpine region but there are shortcomings in spring and summer in the alpine regions.

The proposed adjustment of precipitation events by the ECMWF-ECHAM4 ratio $k$ is a pragmatic and simple approach to adjust the weak reproduction of the course of annual precipitation and its absolute values. More sophisticated techniques and algorithms for precipitation adjustment can be defined. As long as global climate models like ECHAM4 are unable to reproduce the course of annual precipitation correctly, application of downscaled precipitation fields to hydrological models must be adjusted, e.g. through the proposed climatological ECMWF-ECHAM4 $k$ ratio. This allows, at least, the detection of the climate change signal (i.e. trends), even if absolute values observed are not reproduced properly for specific months.

\section{Uncertainty analysis: influence of variability of ECMWF-ECHAM4 ratio}

How much, then, does the variability of the ECMWFECHAM4 $k$ ratio and the respective precipitation adjustment influence simulated runoff? To investigate this question, additional simulations with disturbed ratio $k$ have been performed; MM5_1992-99 was repeated once with $k+\sigma_{k}$ and once with $k-\sigma_{k}$. The results are shown for gauge 6 (Peissenberg) in Fig. 18(a) and for gauge 7 (Weilheim) in Figure 18(b); the uncertainty caused by the variability of the ECMWF-ECHAM4 ratio $k$ is low. Also, for the pre-alpine sub-catchments, even in summer with high $k$ values, it is possible to reproduce observed runoff characteristics reasonably.

\section{Summary and conclusion}

In addition to the detailed changes in runoff frequency distribution, the following general trends can be inferred for the projected future climate scenario; summer runoff 

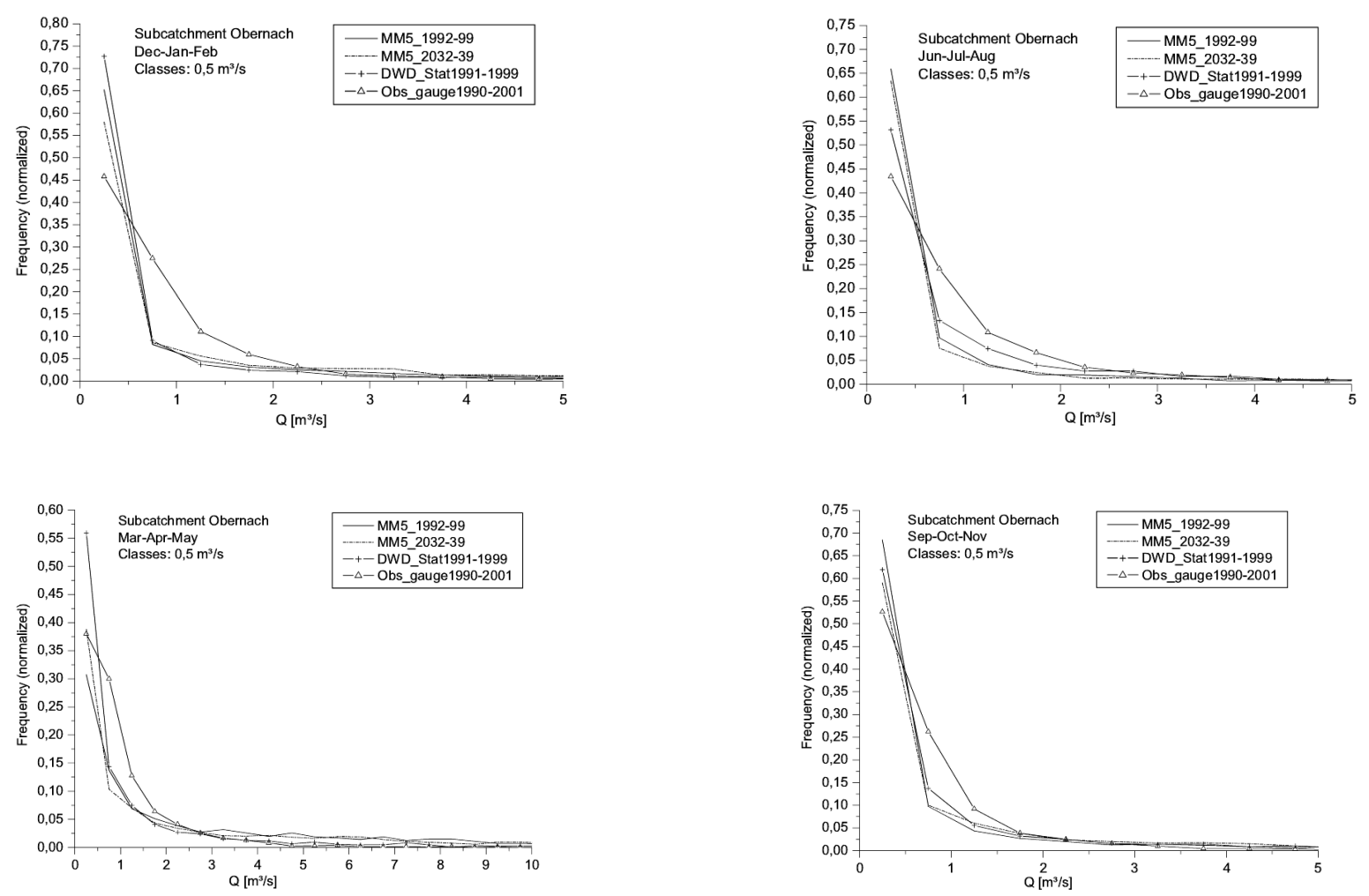

Fig. 17. Comparison between observed FD, station driven modelled FD, and ECHAM4-MCCM driven FDs for 1992-1999 and 2032-2039 at gauge Obernach (sub-catchment 4). (a) winter, (b) spring, (c) summer, (d) autumn
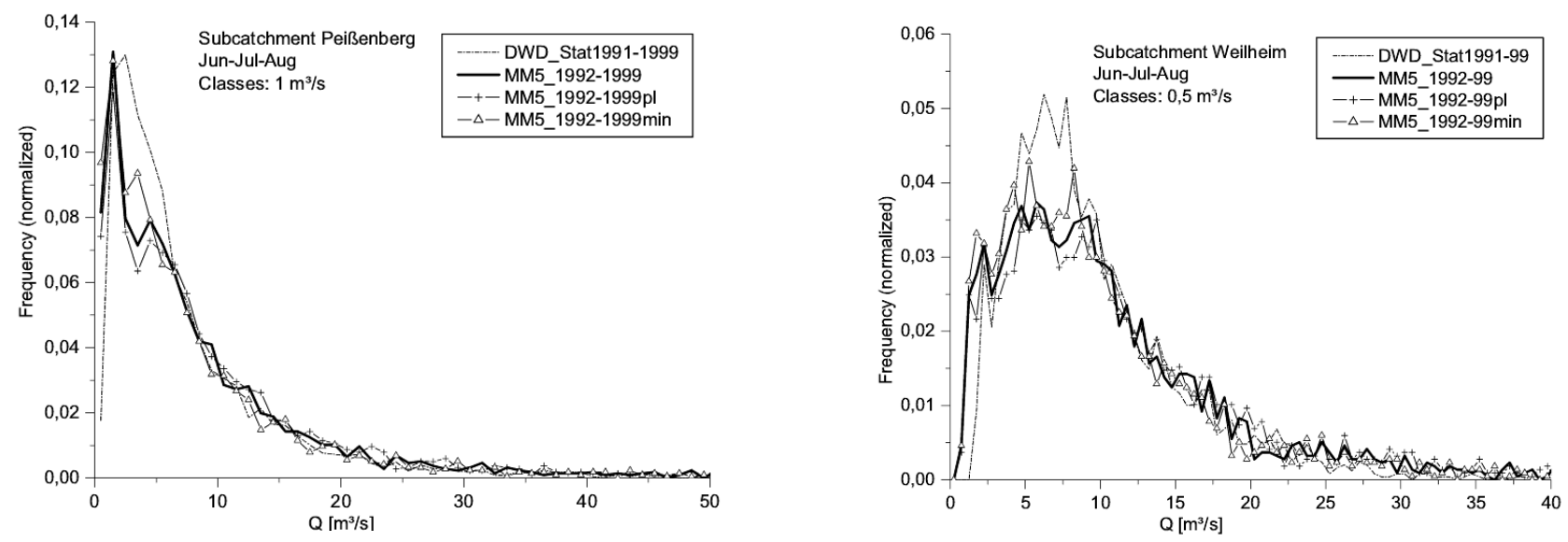

Fig. 18. Uncertainty analysis for variability of scaling factor for summer months (JJA): FD of discharge at (a) gauge Peissenberg (subcatchment 6) and (b) Weilheim (sub-catchment 7); comparison between station driven modelled FD, and ECHAM4/MCCM-driven FDs for 1992-1999 mean and plus/minus one standard deviation. 
from most sub-catchments in the Ammer catchment will decrease, largely because of increased evapotranspiration However, there are regional differences and even neighbouring catchments can differ significantly in their response to global climate change (Fig. 17). Due to the warmer winter temperatures, more precipitation falls as rain rather than as snow and this enhances winter runoff. Also, warmer temperatures in the future climate impose an earlier initiation of snow melt. Hence, present climate runoff peaks in the early summer months will be shifted towards spring and winter months. As accumulation and depletion of snow are particularly important in the alpine areas, the most serious changes in runoff characteristics will take place in the southern, mountainous sub-catchments, whereas slightly damped changes will occur in the northern catchments.

The proposed methodology, i.e. coupled dynamic regional climate modelling and distributed hydrological modelling, is extremely CPU-intensive. This limited the length of the time slices investigated (nine years in this study), especially when high resolutions of the regional climate model are required to account for orographic effects that determine the regional climate in mountainous regions.

Applying the results from ECHAM4 for hydrological impact analyses in central Europe suffers from the fact that ECHAM4 produces too little precipitation in summer months. This leads to a weak reproduction of the annual course of precipitation (precipitation maximum in winter instead of summer). This large-scale shortcoming could not be corrected by the downscaling itself, since the air masses entering central Europe do not carry sufficient moisture. Regional climate models cannot correct this weak reproduction of atmospheric humidity. As long as global climate models like ECHAM4 are unable to describe the annual precipitation course correctly, hydrological impact analysis must use correcting techniques. One pragmatic and simple method has been suggested here and its limits and potentials were discussed. The quality of the simulated runoff frequency statistics was in general higher in the flat pre-alpine regions and in autumn and winter.

In future, longer time slices should be used to improve the statistics of derived means and variances. Moreover, additional driving GCMS (like HadCM3) and different IPCC scenarios (like SRES scenarios A1, A2 and B1, B2) should be applied to coupled regional climate/hydrology simulations to allow the derivation of output ranges and thereby quantify the uncertainty due to GCM model physics and specific emission scenarios.

\section{Acknowledgement}

This work was partially performed under the framework of the Centre of Numerical Environmental Simulation and funded by the Bavarian High Tech Initiative. Additional funding came from the BayForUV-program of the state of Bavaria. Their support is gratefully acknowledged. The support of Jörg Schulla and Karsten Jasper in applying WaSiM was highly appreciated. Special thanks also go to Markus Hannweber of the Wasserwirtschaftsamt Weilheim, who provided runoff data and local expertise, and to Joseph Intsiful and Nicole Acher for proof-reading the article.

\section{References}

Anderson, E., 1973. National Weather River Forecast SystemSnow Accumulation and Ablation Model. NOAA, Tech. Mem., NWS-Hydro-17, U.S. Department of Commerce, USA.

Arnell, N., 1998 The effect of climate change on hydrological regimes in Europe: a continental perspective. Global Environ. Change, 9, 5-23.

Bardossy, A., Stehlik, J. and Caspary, H.-J., 2002. Automated objective classification of daily circulation patterns for precipitation and temperature downscaling based on optimized fuzzy rules. Climate Res., 23, 11-22.

BayFORKLIM, 1996. Klimaatlas von Bayern. Bayerischer Klimaforschungsverbund, ISBN-3-00-000638-9, München, Germany.

Braun, L.N., 1985. Simulation of snowmelt-runoff in lowland and lower alpine regions of Switzerland. Zürcher Geographische Schriften, ETH Zürich, 21, 166pp.

Brutsaert, W., 1982. Evaporation into the Atmosphere. Kluwer, Dordrecht, The Netherlands.

Burlando, P. and Rosso, R., 2002a. Effects of transient climate change on basin hydrology. 1. Precipitation scenarios for the Arno River, central Italy. Hydrol. Process., 16, 1151-1175.

Burlando, P. and Rosso, R., 2002b. Effects of transient climate change on basin hydrology. 2. Impacts on runoff variability in the Arno River, central Italy. Hydrol. Process., 16, 1177-1199.

Burk, S. and Thompson, W., 1989. A vertically nested regional numerical prediction model with second order closure physics. Mon. Weather Rev., 117, 2305-2324.

CC-HYDRO, 1999. Impact of climate change on river basin hydrology under different climatic conditions. Final report, EU Project ENV4-CT95-0133.

Doherty, J., 2002. PEST - Model-Independent Parameter Estimation, Watermark Numerical Computing, Australia.

Fuentes, U. and Heimann, D., 2000. An Improved StatisticalDynamical Downscaling Scheme and its Application to the Alpine Precipitation Climatology. Theor. Appl. Climatol., 65, 119-135.

Green, W.H. and Ampt, G.A., 1911. Studies on Soil Physics: I. The flow of air and water through soils. J. Agr. Sci., 4, 1-24.

Grell, G., Dudhia, J. and Stauffer, D., 1994. A description of the fifth generation Penn State/mesoscale model (MM\%). NCAR Technical Note-398+STR, 117pp.

Grell, G., Emeis, S., Stockwell, W.R., Schoenemeyer, T., Forkel, R., Michalakes, J., Knoche, R. and Seidl, W., 2000a. Application of a Multiscale, Coupled MM5/Chemistry Model to the Complex Terrain of the VOTALP Valley Campaign. Atmos. Environ., 34, 1435-1453. 
Grell, G., Sce, L., Knoche, R., Pfeiffer, A. and Egger, J., 2000 b. Nonhydrostatic climate simulations of precipitation over complex terrain. J. Geophys. Res., D105, 29595-29608.

Kleinn, J., 2002. Climate Change and Runoff Statistics in the Rhine Basin: A Process Study with a Coupled Climate-Runoff Model. Diss. ETH No. 14663, Zürich, Switzerland.

Kunstmann, H. and Stadler, C., 2003. Gekoppelte hochaufgelöste Meteorologie-Hydrologie-Simulationen für das alpine Einzugsgebiet der Mangfall. Hydrologie und Wasserbewirtschaftung, 47, 151-158.

Liepert, B. and Lohmann, U., 2001. A Comparison of Surface Observations and ECHAM4-GCM Experiments and its Relevance to the Indirect Aerosol Effect. J. Climate, 14, 10781091.

Ludwig, R., 2000. Die flächenverteilte Modellierung von Wasserhaushalt und Abflussbildung im Einzugsgebiet der Ammer. Münchner Geographische Abhandlungen, Band 32, München, Germany.

Menzel, L., Niehoff, D., Burger, G. and Bronstert, A., 2002. Climate change impacts on river flooding: A modelling study of three meso-scale catchments. In: Climate Change: Implications for the Hydrological Cycle and Water Management, M. Beniston (Ed.), Kluwer, Dordrecht, The Netherlands. 249269.

Monteith, J.L., 1975. Vegetation and the Atmosphere, Vol. 1: Principles. Academic Press, London, UK.

Peschke, G., 1987. Soil moisture and runoff components from a physically founded approach. Acta hydrophys., 31, 191-205.

Philip, J.R., 1969. The theory of infiltration. In: Advances in Hydrosciences, V.T.Chow, (Ed.). Academic Press, New York, USA. 216-296.

Prudhomme, C., Renard, N. and Crooks, S., 2002. Downscaling of global climate models for flood frequency analysis: where are we now? Hydrol. Process., 16, 1137-1150.

RAPHAEL, 2000. Runoff and Atmospheric Processes for Flood
Hazard Forecasting and Control, EU project ENV4-CT97-0552 Richards, L.A., 1931. Capillary conduction of liquids through porous medium. Physics, 1, 318-333.

Roeckner, E., Arpe, K., Bengtsson, L., Christoph, M., Claussen, M., Dumenil, L., Esch, M., Gioretta, M., Schlese, U. and Schultz-Weida, U., 1996. The atmospheric general circulation model ECHAM4: Model description and simulation of the present-day climate. Report 218, MPI f. Meteorology, Hamburg, Germany.

Schulla, J., 1997. Hydrologische Modellierung von Flussgebieten zur Abschätzung der Folgen von Klimaänderungen. Diss. ETH 12018, Verlag Geographisches Institut ETH Zürich, 187 S.

Schulla, J. and Jasper, K., 2000. Model Description WASIM-ETH (Water Balance Simulation Model ETH), ETH-Zurich, Zurich, Switzerland.

Smirnova, T.G., Brown, J.M. and Benjamin, S.G., 1997. Performance of different soil model configurations in simulating ground temperature and surface fluxes. Mon. Weather Rev., 125, $1870-1884$.

Stehlik, J. and Bardossy, A., 2002. Multivariate stochastic downscaling model for generating daily precipitation series based on atmospheric circulation. J. Hydrol., 256, 120-141.

Van Genuchten, M., 1976. A Closed Form Equation for Predicting the Hydraulic Conductivity of Unsaturated Soils. Amer. J. Soil Sci., 44, 892-898.

Westrick, K., Storck, P. and Mass, C., 2002. Description and evaluation of a hydrometeorological forecast system for mountainous Watersheds. Weather Forecast., 17, 250-262 .

Wigmosta, M.S., Vail, L.W. and Lettenmaier, D.P., 1994. A distributed hydrology-soil-vegetation model for complex terrain. Water Resour. Res., 30, 1665-1679.

Yu, Z., Lakhtakia, M., Yarnal, B., White, R., Miller, D. and Frakes, B., 1999. Simulating the river-basin response to atmospheric forcing II. Linking a mesoscale meteorological model and a hydrological model system. J. Hydrol., 218, 72-91. 